\title{
Erratum zu: Das Schiff Europa - Europe's Ship of States: Über eine Kippfigur der Integration
}

\author{
Stephan Leibfried · Susan M. Gaines · Lorraine Frisina
}

Nach der Veröffentlichung des Beitrages bat uns der Autor, folgende Änderungen zu seinem Manuskript zu veröffentlichen:

S. 393, Text zu Abb. 1, letzter Satz: „... Wir danken dem GCMF für die elektronische Version dieser Abbildung.)“

S. 405, Fußnote 25, 1. Zeile: „Das Lissabon-Urteil (siehe Fußnote 19) macht dieses Ziel auch definitorisch deutlich (Randnr. 229): ...“"

S. 417, Text zu Abb. 8, 1.-3. Zeile: „Vor-Bilder zum ,Ausflug auf die Medway“ I - Der Bildauszug zeigt im Hintergrund ..."“

S. 418, Text zu Abb. 9, 1.-17. Zeile: „Vor-Bilder zum ,Ausflug auf die Medway“ II - Das Bild von Abraham Stock wurde 1670 wahrscheinlich nach dieser Federzeichnung von Willem v.d. Velde de Oude Krijgsraad voor de 4daagschen zeeslag aan board v/h Admiraal/Ship van M.A. Ruyter, de Seven Provinziën' 10. Juni 1666 gemalt (Rijksmuseum, Amsterdam). Willem v. d. Velde war mit Billigung von Admiral Michiel A. de Ruyter unmittelbar vor Beginn der 4-Tage-Schlacht im Juni 1666 als ,embedded artist" auf hoher See an Bord der Die Sieben Provinzen.“

S. 418, 4.-5 Zeile: „Einheit und Wohlstand der sieben Provinzen scheinen mit der Reformierten-Synode von Dordrecht 1618/1619 nach erbitterten Kämpfen erreicht“".

S. 419, Text zu Abb. 10, 2.-3. Zeile: „Frans Schillemans (geboren um 1575 - ?), Het Schip van Staat - Das Staatsschiff, Stich von 1620 (Museum Boijmans Van Beuningen in Rotterdam, Inventurnr. L1989/1). Die langen erklärenden, durchgehend niederländischen

(C) VS-Verlag 2009

Die Onlineversion des Originalbeitrages ist ereichbar unter doi:10.1007/s11578-009-0055-0

Prof. Dr. S. Leibfried $(\bowtie)$

Professor der Politikwissenschaften und Sprecher des Sfb

Staatlichkeit im Wandel (Sfb 597) der Universität Bremen, Bremen, Deutschland

E-Mail: stephan.leibfried@sfb597.uni-bremen.de

S. M. Gaines

Schriftstellerin und Übersetzerin beim Sfb 597 in Bremen, Bremen, Deutschland

Dr. L. Frisina

Politikwissenschaftlerin und wissenschaftliche Mitarbeiterin des Sfb 597 in der vergleichenden Gesundheitsforschung, Bremen, Deutschland 
Passagen am rechten und linken Rand und die dem gleichen Zweck dienenden lateinischen Passagen unter dem Bild sind weggelassen worden, weil sie hier unlesbar sein würden. Die weggelassene Bildüberschrift lautete: IDEA BELGICARUM PROVINCIARUM CONFÆDERATARUM (Idee der verbündeten belgischen Provinzen).“ 